ORIGINAL ARTICLE

\title{
Long term effects of exposure to automobile exhaust on the pulmonary function of female adults in Tokyo, Japan
}

\author{
K Sekine, M Shima, Y Nitta, M Adachi
}

Occup Environ Med 2004;61:350-357. doi: 10.1136/oem.2002.005934

See end of article for authors' affiliations

Correspondence to:

Dr M Shima, Department of Public Health, Graduate School of Medicine, Chiba University, 1-8-1 Inohana, Chuo-ku, Chiba 260-

8670, Japan; shima-m@

faculty.chiba-u.jp

Accepted

8 September 2003

\begin{abstract}
Aims: To investigate the chronic effects of air pollution caused mainly by automobiles in healthy adult females.

Methods: Respiratory symptoms were investigated in 5682 adult females who had lived in the Tokyo metropolitan area for three years or more in 1987; 733 of them were subjected to pulmonary function tests over eight years from 1987 to 1994. The subjects were divided into three groups by the level of air pollution they were exposed to during the study period. The concentrations of nitrogen dioxide and suspended particulate matter were the highest in group 1, and the lowest in group 3.

Results: The prevalence rates of respiratory symptoms in group 1 were higher than those in groups 2 and 3 , except for wheezing. Multiple logistic regression analysis showed significant differences in persistent phlegm and breathlessness. The subjects selected for the analysis of pulmonary function were 94, 210, and 102 females in groups 1, 2, and 3, respectively. The annual mean change of $F E V_{1}$ in group 1 was the largest $(-0.020 \mathrm{l} / \mathrm{y})$, followed by that in group $2(-0.015 \mathrm{l} / \mathrm{y})$, and that in group $3(-0.009 \mathrm{l} / \mathrm{y})$. Testing for trends showed a significant larger decrease of $\mathrm{FEV}_{1}$ with the increase in the level of air pollution. Conclusions: The subjects living in areas with high levels of air pollution showed higher prevalence rates of respiratory symptoms and a larger decrease of $\mathrm{FEV}_{1}$ compared with those living in areas with low levels of air pollution. Since the traffic density is larger in areas with high air pollution, the differences among the groups may reflect the effect of air pollution attributable to particulate matter found in automobile exhaust.
\end{abstract}

$\mathrm{N}$ owadays, people cannot evade the global problem of environmental pollution caused by automobile exhaust so long as they live in urban areas. In Japan, along with the concentration of the population and production in large cities, air pollution in the districts along trunk roads is now causing a serious problem. The major components of air pollution in urban districts in Japan are nitrogen dioxide $\left(\mathrm{NO}_{2}\right)$ and suspended particulate matter (SPM) emitted mainly by automobiles. ${ }^{1-3}$ Air pollution in the districts along main roads has shown hardly any sign of improvement. In particular, the exhaust from diesel engines is considered substantial in this regard. Larger sized diesel engines emit 2-30 times more nitric oxide and 30-100 times more SPM than gasoline engines. ${ }^{4-6}$ Therefore, diesel engines constitute a major cause of air pollution attributable to $\mathrm{NO}_{2}$ and SPM. It is reported that Tokyo, the capital of Japan, has the largest number of vehicles (2 690000 in 1990), and the annual mean concentrations of $\mathrm{NO}_{2}$ and SPM in the air in Tokyo are $0.030 \mathrm{ppm}$ and $52 \mu \mathrm{g} / \mathrm{m}^{3}$, respectively; that is, higher than the national means of $0.016 \mathrm{ppm}$ and $37 \mu \mathrm{g} / \mathrm{m}^{3}$, respectively.

There have been many studies on the influence of air pollution on children's pulmonary function, and it has been reported that in areas of high concentration of nitric oxide, the values of children's pulmonary function parameters are low and their growth is comparatively delayed..$^{7-10}$ However, there is little data on the effects of air pollution on pulmonary function in adults. In traffic workers, several studies have shown an association between exposure to automobile exhaust and adverse effects on respiratory symptoms and pulmonary function, ${ }^{11-13}$ whereas others failed to find such an association. ${ }^{14-15}$ In this way, the results of studies on the effects of air pollution are not conclusive. Hardly any community based research has been conducted to investigate the long term effects of air pollution on pulmonary function.
We carried out a cross-sectional study to investigate respiratory symptoms in adult females who lived in the Tokyo metropolitan area, and performed a longitudinal study of annual pulmonary function tests for eight years from 1987 to 1994. Based on these studies, we evaluated the long term influence of air pollutants, mainly automobile exhaust, on pulmonary function.

\section{SUBJECTS AND METHODS}

Study areas and subjects

We covered almost the whole Tokyo metropolitan area by investigating the nine districts shown in fig 1 (Chuo ward, Ohta ward, Shibuya ward, Itabashi ward, Hachioji City, Tachikawa City, Ome City, Machida City, Tanashi City). The daytime average traffic density of trunk roads in these districts $^{16}$ was 8000-32 000 vehicles every 12 hours in 1990 (table 1).

In each district, the area close to the edge of a trunk road ("roadside area"; within $20 \mathrm{~m}$ from the road) and the hind land ("area behind the road", >20 m-<150 m) were investigated. The subjects, 500 females, 30-59 years old, were randomly selected from the inhabitants register of each area, and the respiratory symptoms were investigated in those who had lived in a given area for three years or more. One hundred females who did not smoke and who did not have a history of respiratory diseases were then randomly selected from among the females in each district, and subjected to pulmonary function tests. The objective and

Abbreviations: DEP, diesel exhaust particle; $\mathrm{FEV}_{1}$, forced expiratory volume in 1 second; $F V C$, forced vital capacity; $\mathrm{NO}_{2}$, nitrogen dioxide; $\mathrm{PM}_{10}$, particulate matter less than $10 \mu \mathrm{g}$ in diameter; SPM, suspended particulate matter 


\section{Main messages}

- The prevalence of respiratory symptoms and the longitudinal changes of pulmonary function among adult females were investigated relative to air pollution caused mainly by automobiles.

- The prevalence rates of respiratory symptoms were high among the subjects living in areas with high levels of air pollution.

- The annual mean changes of $\mathrm{FEV}_{1}$ were significantly greater in females living in areas with higher levels of air pollution.

method of this study were fully explained to the subjects, and informed consent was obtained from them before the study.

\section{Air monitoring}

Air environment measurement devices were installed at $0 \mathrm{~m}$ and $20 \mathrm{~m}$ from the edge of trunk roads, and the concentration of air pollutants was measured every month for three consecutive days. $\mathrm{NO}_{2}$ concentrations were measured using the PTIO method..$^{17}$ For measurement of SPM, particulate matter less than $10 \mu \mathrm{m}$ in diameter was collected by a low volume air sampler for 72 hours.

\section{Respiratory symptoms}

The questionnaire employed was a modified Japanese version of ATS-DLD-78. ${ }^{18}$ It was sent by mail to each subject between July and August 1987. They were collected after about 1-2 weeks by the staff engaged in the investigation who visited each home and verified that the questionnaires had been filled in properly.

\section{Pulmonary function tests}

Skilled staff conducted the pulmonary function tests in the community centre in each area once a year (AugustNovember) using an electronic spirometer (DISCOM-21, Chest Inc., Tokyo, Japan). Prior to each test the device was calibrated using a 3-litre syringe. After sufficient explanation on the method, the subjects were repeatedly tested, with a short interval, until more than three forced expiratory curves that were reproducible had been obtained (maximum eight times). A nose clip was applied to each subject, and subjects were in the standing position during the tests.

Table 1 Daytime average traffic density of the trunk roads in study areas

\begin{tabular}{|c|c|c|c|}
\hline \multirow[b]{2}{*}{ Area } & \multirow[b]{2}{*}{ Trunk roads } & \multicolumn{2}{|c|}{ Traffic density (1990) } \\
\hline & & $\begin{array}{l}\text { All (vehicles/ } \\
12 \text { hours) }\end{array}$ & $\begin{array}{l}\text { Heavy vehicles } \\
\text { (vehicles/ } \\
12 \text { hours) }\end{array}$ \\
\hline Chuo ward & Kiyosumi avenue & 24100 & 5724 \\
\hline Ohta ward & Route 131 & 24172 & 6612 \\
\hline Shibuya ward & Yamate avenue & 32881 & 4152 \\
\hline Itabashi ward & Route 17 & 30884 & 6949 \\
\hline Tanashi City & Shinoume street & 28821 & 5018 \\
\hline $\begin{array}{l}\text { Hachioji City } \\
\text { Tachikawa }\end{array}$ & Route 20 bypass & 20397 & 2681 \\
\hline City & Tachikawa avenue & 10216 & 1730 \\
\hline Machida City & Machida street & 13816 & 1742 \\
\hline Ome City & Okutama street & 8641 & 1690 \\
\hline
\end{tabular}

\section{Policy implications}

- The differences in respiratory symptoms and pulmonary function among the areas may reflect the effect of air pollution attributable to particulate matter found in automobile exhaust.

- The chronic effects of air pollution on the respiratory health of people living in urban areas should be further clarified.

\section{Data analysis}

Classification by degree of air pollution

The roadside areas and the areas behind the roads (18 areas in total) in nine districts were classified into the following three groups by the level of air pollution (mean $\mathrm{NO}_{2}$ and mean SPM concentrations) during the study period (table 2). Since $\mathrm{NO}_{2}$ concentrations showed a smaller standard deviation and range to the SPM concentrations, and reflected the differences among areas quite well, the classification was mainly based on the $\mathrm{NO}_{2}$ concentration, with consideration of the SPM concentration.

- Group 1: This group consisted of roadside areas in five districts (Chuo ward, Ohta ward, Shibuya ward, Itabashi ward, Tanashi City) where both $\mathrm{NO}_{2}$ (mean 0.047$0.056 \mathrm{ppm}$ ) and SPM (mean $48-62 \mu \mathrm{g} / \mathrm{m}^{3}$ ) concentrations were high. The daytime average traffic density (in 1990) exceeded 20000 vehicles including 4000 large vehicles in each of these districts.

- Group 2: This group consisted of roadside areas in three districts (Hachioji City, Tachikawa City, Machida City) where both $\mathrm{NO}_{2}$ (mean $0.038-0.046 \mathrm{ppm}$ ) and SPM (mean $38-46 \mu \mathrm{g} / \mathrm{m}^{3}$ ) concentrations were moderate and the areas behind the roads in the five districts of group 1 . The traffic density in the roadside areas was 10000 20000 vehicles, including $<3000$ large vehicles.

- Group 3: This group consisted of areas close to the roads and those behind the roads in one district (Ome City)

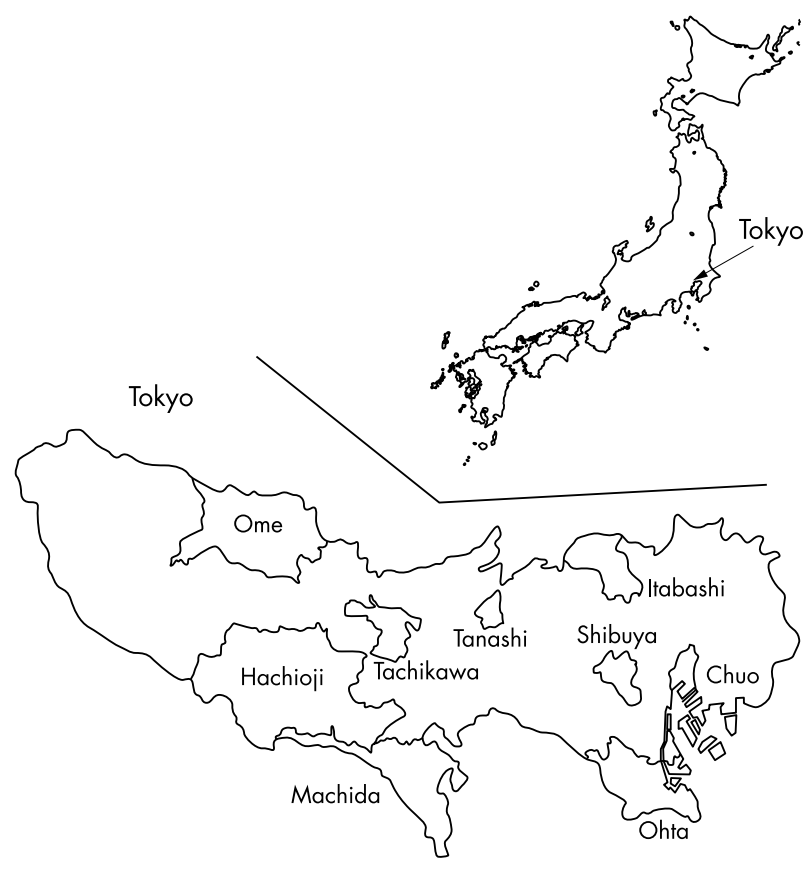

Figure 1 Location of the study areas. 
Table 2 Air pollution average concentration of the sampled areas

\begin{tabular}{|c|c|c|c|c|c|c|c|c|c|c|}
\hline \multirow[b]{2}{*}{ Area } & \multirow{2}{*}{$\begin{array}{l}\text { Distance from } \\
\text { roadway }\end{array}$} & \multicolumn{4}{|c|}{$\mathrm{NO}_{2}$ concentration $(\mathrm{ppb})^{*}$} & \multicolumn{4}{|c|}{ SPM concentration $\left(\mu \mathrm{g} / \mathrm{m}^{3}\right) \dagger$} & \multirow[b]{2}{*}{ Group } \\
\hline & & $\mathbf{n}$ & Mean & SD & Range & $\mathbf{n}$ & Mean & SD & Range & \\
\hline \multirow[t]{2}{*}{ Chuo ward } & $0 \mathrm{~m}$ & 51 & 51.6 & 7.8 & $33-65$ & 87 & 47.6 & 16.8 & $19.2-99.8$ & 1 \\
\hline & $20 \mathrm{~m}$ & 32 & 44.0 & 9.0 & $27-64$ & 87 & 43.3 & 18.0 & $16.3-95.8$ & 2 \\
\hline \multirow[t]{2}{*}{ Ohta ward } & $0 \mathrm{~m}$ & 51 & 52.0 & 12.1 & $27-83$ & 87 & 51.6 & 18.6 & $12.1-102.3$ & 1 \\
\hline & $20 \mathrm{~m}$ & 51 & 45.7 & 10.3 & $25-75$ & 87 & 46.4 & 16.8 & $21.1-100.8$ & 2 \\
\hline \multirow[t]{2}{*}{ Shibuya ward } & $0 \mathrm{~m}$ & 51 & 56.1 & 10.1 & $33-77$ & 87 & 61.8 & 21.7 & $30.2-131.0$ & 1 \\
\hline & $20 \mathrm{~m}$ & 51 & 42.6 & 10.2 & $24-75$ & 85 & 38.8 & 15.7 & $10.6-94.8$ & 2 \\
\hline \multirow[t]{2}{*}{ Itabashi ward } & $0 \mathrm{~m}$ & 51 & 53.6 & 12.0 & $30-80$ & 87 & 59.2 & 23.0 & $22.5-140.6$ & 1 \\
\hline & $20 \mathrm{~m}$ & 32 & 44.0 & 10.6 & $24-67$ & 87 & 45.7 & 19.8 & $9.9-112.2$ & 2 \\
\hline \multirow[t]{2}{*}{ Tanashi City } & $0 \mathrm{~m}$ & 47 & 47.2 & 9.7 & $29-65$ & 85 & 56.8 & 23.9 & $11.1-135.5$ & 1 \\
\hline & $20 \mathrm{~m}$ & 26 & 37.8 & 9.2 & $23-54$ & 83 & 46.0 & 22.3 & $7.3-108.2$ & 2 \\
\hline \multirow[t]{2}{*}{ Hachioji City } & $0 \mathrm{~m}$ & 51 & 38.7 & 8.2 & $24-57$ & 85 & 44.3 & 15.5 & $16.8-82.2$ & 2 \\
\hline & $20 \mathrm{~m}$ & 32 & 32.8 & 6.6 & $21-43$ & 87 & 39.4 & 13.7 & $10.5-82.5$ & 3 \\
\hline \multirow[t]{2}{*}{ Tachikawa City } & $0 \mathrm{~m}$ & 50 & 41.8 & 9.8 & $24-59$ & 75 & 45.1 & 17.4 & $15.4-88.6$ & 2 \\
\hline & $20 \mathrm{~m}$ & 32 & 33.9 & 8.2 & $19-46$ & 75 & 38.9 & 14.4 & $11.0-77.1$ & 3 \\
\hline \multirow[t]{2}{*}{ Machida City } & $0 \mathrm{~m}$ & 51 & 40.1 & 9.0 & $23-56$ & 87 & 43.1 & 17.9 & $11.1-108.1$ & 2 \\
\hline & $20 \mathrm{~m}$ & 31 & 35.6 & 8.2 & $22-51$ & 82 & 33.9 & 15.8 & $5.0-74.7$ & 3 \\
\hline \multirow[t]{2}{*}{ Ome City } & $0 \mathrm{~m}$ & 51 & 29.0 & 6.0 & $18-49$ & 87 & 34.5 & 14.7 & $7.3-89.2$ & 3 \\
\hline & $20 \mathrm{~m}$ & 32 & 23.5 & 5.4 & $14-33$ & 87 & 28.1 & 13.8 & $3.4-69.7$ & 3 \\
\hline
\end{tabular}

where both $\mathrm{NO}_{2}$ (mean 0.024-0.036 ppm) and SPM (mean 28-39 $\mu \mathrm{g} / \mathrm{m}^{3}$ ) concentrations were low, as well as the areas behind the roads in districts of group 2. The traffic density in the roadside areas in Ome City was 864 lvehicles, which was smaller than the density observed in other districts.

\section{Investigation of respiratory symptoms}

Six items (age, years of residence in the area, job status, smoking habit, type of heater, and housing structure) were compared among the three groups. Significance was evaluated by the $\chi^{2}$ test.

(a) The prevalence of respiratory symptoms was compared among the three groups. Respiratory symptoms were determined from questionnaire responses defined as follows: (1) persistent cough: for $\geqslant 3$ months a year, cough almost every day; (2) persistent phlegm: for $\geqslant 3$ months a year, phlegm almost every day; (3) wheeze: twice or more times in the past two years, wheezing or rattling when the subject had a cold or even when she did not have a cold; (4) asthma: diagnosed by a physician and history of $\geqslant 2$ attacks accompanied with respiratory difficulty in the past, and an attack or treatment for asthma in the past two years; (5) breathlessness: breathing difficulty in walking a flat road and not catching up with people of the same generation.

(b) We used multiple logistic regression analysis (adjusted for age, years of residence in the area, etc) to calculate odds ratios for the above five symptoms compared with the status in group 3. We also evaluated the trend of the hypothesis group $1>$ group $2>$ group 3 . The LOGIST procedure of the SAS statistics package was employed for the calculation. ${ }^{19}$

\section{Pulmonary function tests}

Those who provided valid data on four or more of the eight tests performed in addition to the valid data in the initial test were subjected to pulmonary function tests. Their age, height, forced vital capacity (FVC), forced expiratory volume in 1 second $\left(\mathrm{FEV}_{1}\right)$, and respiratory symptoms at the time of the initial test were compared between the subjects included in the analysis of pulmonary function tests and those excluded from the analysis.

$\mathrm{FVC}$ and $\mathrm{FEV}_{1}$ were used as indices of pulmonary function. The age and height adjusted mean levels were obtained and annual mean changes were compared among the three groups. The mean levels of these indices were obtained from each group after adjusting them for age, square of age, height, years of residence in the area, housing structure, job status, and type of heater; the results were compared with those of group 3 in which the air pollution level was the lowest.

There seemed to be an autocorrelation of individual pulmonary function levels between the years investigated. Accordingly, the annual mean changes of FVC and FEV 1 were analysed in a two stage analysis. First, based on the progressive decrease of FVC and $\mathrm{FEV}_{1}$ over the follow up years in each subject, the regression coefficient was assumed as the individual annual mean changes. Then, with this annual mean change as the dependent variable, covariance analysis was carried out using a general linear model (GLM procedure of SAS)..$^{20}$ The factors analysed were the group, pulmonary function at the initial test, age and height at the time of the initial test, number of years investigated, years of residence in the area, type of heater, housing structure, and job status. Using the above mentioned model, the adjusted annual mean change was obtained for each of the three groups, and the hypothesis of group $1>$ group $2>$ group 3 was evaluated.

\section{RESULTS}

\section{Investigation of respiratory symptoms}

The number of questionnaires recovered was 6760 (the recovery rate was $73.3 \%$ in group $1,77.5 \%$ in group 2 , and $75.8 \%$ in group 3 ). Since those who lived less than three years in an area $(n=478)$ and those whose answers to the questions used for the analysis were inaccurate $(n=600)$ were excluded, data from 5682 subjects (1147 in group 1, 2695 in group 2, and 1840 in group 3) were analysed. The percentage of subjects analysed was $84.1 \%$ of the total number of people who answered the questionnaire, and $63.8 \%$ of the initially included subjects.

Table 3 shows the prevalence of relevant factors by group. Significant differences among the three groups were observed in age, years of residence in the area, job status, smoking 
Table 3 Characteristics of the subjects who answered the questionnaire, by area

\begin{tabular}{|c|c|c|c|c|c|c|c|}
\hline & \multicolumn{2}{|c|}{$\begin{array}{l}\text { Group } 1 \\
(n=1147)\end{array}$} & \multicolumn{2}{|c|}{$\begin{array}{l}\text { Group } 2 \\
(n=2695)\end{array}$} & \multicolumn{2}{|c|}{$\begin{array}{l}\text { Group } 3 \\
(n=1840)\end{array}$} & \multirow[b]{2}{*}{$p$ value } \\
\hline & $\mathbf{n}$ & $\%$ & n & $\%$ & $\mathbf{n}$ & $\%$ & \\
\hline Age (y) & & & & & & & 0.001 \\
\hline $30-39$ & 363 & 31.6 & 730 & 27.1 & 580 & 31.5 & \\
\hline $40-49$ & 388 & 33.8 & 909 & 33.7 & 628 & 34.1 & \\
\hline $50-59$ & 396 & 34.5 & 1056 & 39.2 & 632 & 34.3 & \\
\hline Years of residence in the area & & & & & & & $<0.001$ \\
\hline $3-9$ & 431 & 37.6 & 713 & 26.5 & 620 & 33.7 & \\
\hline $10+$ & 716 & 62.4 & 1982 & 73.5 & 1220 & 66.3 & \\
\hline Job status & & & & & & & $<0.001$ \\
\hline Currently employed & 721 & 62.9 & 1479 & 54.9 & 1000 & 54.3 & \\
\hline Past employed & 222 & 19.4 & 635 & 23.6 & 480 & 26.1 & \\
\hline Never employed & 204 & 17.8 & 581 & 21.6 & 360 & 19.6 & \\
\hline Smoking habits & & & & & & & 0.004 \\
\hline Current smoker & 241 & 21.0 & 443 & 16.4 & 312 & 17.0 & \\
\hline Past smoker & 52 & 4.5 & 106 & 3.9 & 64 & 3.5 & \\
\hline Never smoked & 854 & 74.5 & 2146 & 79.6 & 1464 & 79.6 & \\
\hline Type of heaters & & & & & & & 0.053 \\
\hline Unvented & 526 & 45.9 & 1345 & 49.9 & 876 & 47.6 & \\
\hline Others or none & 621 & 54.1 & 1350 & 50.1 & 964 & 52.4 & \\
\hline House structures & & & & & & & $<0.001$ \\
\hline Wooden with wooden window frames & 190 & 16.6 & 595 & 22.1 & 381 & 20.7 & \\
\hline Wooden with aluminium window frames & 367 & 32.0 & 1484 & 55.1 & 1037 & 56.4 & \\
\hline Reinforced concrete & 590 & 51.4 & 616 & 22.9 & 422 & 22.9 & \\
\hline
\end{tabular}

habit, and housing structure. With regard to age, those in their 50s accounted for the highest percentage in group 2 . With regard to years of residence in the area, those who lived in the area in question for 10 years or more accounted for $60 \%$ or more in each group, but those in groups 2 and 3 lived longer in the areas in question than those in group 1. With regard to occupation, $62.9 \%$ of the subjects in group 1 had jobs and the proportion was higher than that in the remaining two groups; $79 \%$ of them were engaged in clerical jobs, sales, and service jobs, and few subjects were engaged in the dust work. With regard to smoking status, the proportion of those who smoked in group 1 was higher than that in the remaining two groups. With regard to housing structure, the proportion of those who lived in airtight reinforced concrete buildings in group 1 was the highest among the three groups. With regard to heaters, the proportion of those who used vented heaters was the highest in each group and there were no significant differences among the three groups.

Table 4 shows the prevalence rates of respiratory symptoms by group. The rates in group 1 were higher than that in groups 2 and 3 except for wheezing. According to testing for the trend, significant differences were found in persistent phlegm $(7.7 \%, 5.9 \%$, and $5.1 \%$ in groups 1,2 , and 3 , respectively) and breathlessness $(3.1 \%, 1.0 \%$, and $1.3 \%$ in groups 1, 2, and 3, respectively), among the groups.

Multiple logistic regression analysis was employed to adjust the relevant six factors including age and years of residence in the area. Table 5 shows the adjusted odds ratios relative to group 3. The odds ratios were significantly higher than 1 for persistent phlegm (group l: OR $=1.78,95 \%$ CI 1.26 to 2.53; group 2: $\mathrm{OR}=1.52,95 \%$ CI 1.11 to 2.04 ) and breathlessness (group 1: OR $=2.70,95 \%$ CI 1.48 to 4.91 ). Although the odds ratio of asthma was larger than 1 , it was not significant in group 1 ( $\mathrm{OR}=2.66,95 \%$ CI 0.98 to 7.19 ) and group $2(\mathrm{OR}=1.99,95 \% \mathrm{CI} 0.82$ to 4.83$)$. The trend test revealed significant relationships of breathlessness and persistent phlegm with the level of air pollution $(\mathrm{p}=0.001$ for both).

\section{Pulmonary function tests}

A total of 733 females were subjected to the pulmonary function tests the first time (179, 358, and 196 in groups 1, 2, and 3, respectively). Of them, 406 (94 (52.5\%), 210 (58.7\%), and $102(52.0 \%)$ in groups 1,2 , and 3, respectively) who provided valid data on four or more tests during the investigation period were subjected to the analysis (table 6).

Table 7 compares the characteristics of subjects included in the analysis of each group with those of people excluded from the analysis. The subjects in all three groups were significantly older than those excluded from the analysis but there was no difference in height. Although FVC and $\mathrm{FEV}_{1}$ were slightly higher in the analysis group, there was no significant difference. Since those without a history of respiratory diseases were selected, the proportion of those having respiratory symptoms was extremely low in subjects both included and excluded, and there was no significant difference between them (data not shown).

Table 4 Prevalence of respiratory symptoms among female adults, by area

\begin{tabular}{|c|c|c|c|c|c|c|c|c|}
\hline & \multicolumn{2}{|c|}{$\begin{array}{l}\text { Group } 1 \\
(n=1147)\end{array}$} & \multicolumn{2}{|c|}{$\begin{array}{l}\text { Group } 2 \\
(n=2695)\end{array}$} & \multicolumn{2}{|c|}{$\begin{array}{l}\text { Group } 3 \\
(n=1840)\end{array}$} & \multirow{2}{*}{$\begin{array}{l}\chi^{2} \text { test } \\
p \text { value }\end{array}$} & \multirow{2}{*}{$\begin{array}{l}\text { Cochran-Armitage test } \\
p \text { value }\end{array}$} \\
\hline & $n$ & $\%$ & $n$ & $\%$ & $n$ & $\%$ & & \\
\hline Persistent cough & 36 & 3.1 & 79 & 2.9 & 56 & 3.0 & 0.937 & 0.926 \\
\hline Persistent phlegm & 88 & 7.7 & 160 & 5.9 & 94 & 5.1 & 0.016 & 0.005 \\
\hline Asthma & 12 & 1.0 & 24 & 0.9 & 11 & 0.6 & 0.371 & 0.168 \\
\hline Wheeze & 42 & 3.7 & 105 & 3.9 & 53 & 2.9 & 0.182 & 0.177 \\
\hline Breathlessness & 35 & 3.1 & 28 & 1.0 & 24 & 1.3 & $<0.001$ & 0.001 \\
\hline
\end{tabular}


Table 5 Results of multiple logistic regression analysis for respiratory symptoms

\begin{tabular}{|c|c|c|c|c|}
\hline & Group & OR & $95 \% \mathrm{Cl}$ & $p$ value (trend test) \\
\hline \multirow[t]{3}{*}{ Persistent cough } & Group 3 & 1.00 & & 0.788 \\
\hline & Group 2 & 1.02 & 0.70 to 1.48 & \\
\hline & Group 1 & 1.07 & 0.67 to 1.70 & \\
\hline \multirow[t]{3}{*}{ Persistent phlegm } & Group 3 & 1.00 & & 0.001 \\
\hline & Group 2 & 1.51 & 1.11 to 2.04 & \\
\hline & Group 1 & 1.78 & 1.26 to 2.53 & \\
\hline \multirow[t]{3}{*}{ Asthma } & Group 3 & 1.00 & & 0.052 \\
\hline & Group 2 & 1.99 & 0.82 to 4.83 & \\
\hline & Group 1 & 2.66 & 0.98 to 7.19 & \\
\hline \multirow[t]{3}{*}{ Wheeze } & Group 3 & 1.00 & & 0.186 \\
\hline & Group 2 & 1.39 & 0.95 to 2.01 & \\
\hline & Group 1 & 1.34 & 0.85 to 2.11 & \\
\hline \multirow[t]{3}{*}{ Breathlessness } & Group 3 & 1.00 & & 0.001 \\
\hline & Group 2 & 0.84 & 0.47 to 1.50 & \\
\hline & Group 1 & 2.70 & 1.48 to 4.91 & \\
\hline
\end{tabular}

Figure 2 compares the changes in mean values adjusted for age and height in each group. Although FVC did not show a consistent trend among the groups by the year of investigation, $\mathrm{FEV}_{1}$ in group 1 was the lowest every year.

Figure 3 shows the comparison of adjusted mean values of $\mathrm{FVC}$ and $\mathrm{FEV}_{1}$ of females in group 1 and group 2 with those in group 3, who had been living in areas with the lowest level of air pollution. FVC did not show any specific relation among the groups. Although there was no difference in $\mathrm{FEV}_{1}$ among the groups in the first year, the level started to decrease in group 1 in comparison with group 3, and the difference between the two groups tended to increase with time.

Figure 4 shows the annual mean changes of FVC and $\mathrm{FEV}_{1}$ by group. With regard to FVC, group 1 showed the highest rate of decrease $(0.006 \mathrm{l} /$ year $)$ followed by group 2 (0.002 l/ year) and group $3(0.000 \mathrm{l} /$ year $)$. However, the result of the trend test was not significant $(\mathrm{p}=0.162)$. With regard to $\mathrm{FEV}_{1}$, group 1 showed the highest rate of decrease $(0.020 \mathrm{l} /$ year), followed by group 2 (0.015 l/year) and group 3 (0.009 l/year). The trend test revealed that the higher the level of air pollution, the more significantly the $\mathrm{FEV}_{1}$ was reduced $(\mathrm{p}<0.001)$.

\section{DISCUSSION}

To clarify the chronic effects of air pollution caused mainly by automobiles, on health, pulmonary function tests were conducted for eight years in adult females who lived in various areas of the Tokyo metropolitan area. The decrease in pulmonary function was larger in females who lived in areas close to the trunk roads where the daytime traffic density exceeded 20000 vehicles, than in the other groups.

Compared with agricultural and rural regions, the levels of air pollution are higher in larger cities. The level of air pollution around trunk roads is reportedly the highest in roadside areas, but the farther from the roads an area is, the lower the level of pollution it has. Laxen and Noordally ${ }^{21}$ measured the $\mathrm{NO}_{2}$ concentration, which is a major pollutant arising from automobile exhaust, in the roadside areas in England. They reported that the level rapidly decreased in the areas 10-15 m away from the road and that the level became almost constant when the distance from the road exceeded $30 \mathrm{~m}$. The results of air monitoring in this study also indicated that the highest $\mathrm{NO}_{2}$ and SPM concentrations were in the roadside areas, but the levels gradually decreased with the distance from the road. Although the level also depends on the environmental conditions around an area, including topography and climate, ${ }^{22}$ the distance from the road is clearly the most important factor influencing the level of air pollution in a given area.

Ono and colleagues ${ }^{23}$ measured $\mathrm{NO}_{2}$ and SPM concentrations in areas close to the trunk roads in Tokyo as well as inside the houses in Tokyo. They reported that, the nearer a house was to a road, the higher the indoor $\mathrm{NO}_{2}$ concentration if an unvented heater was not used, and that the influence of unvented heaters was greater during the winter time. Nakai and colleagues ${ }^{24}$ reported that the personal levels of exposure to $\mathrm{NO}_{2}$ also decreased with the distance from the roads. According to the results of this survey, the type of heaters used was similar among the groups. Even if indoor pollution caused by heaters was considered, those who lived in roadside areas seemed to have been exposed to a higher concentration of pollutants in comparison with those who lived farther from the roadside.

Several reports on the effect of automobile exhaust on health have been published. According to these reports, respiratory symptoms, including chronic cough and phlegm, asthma, and allergic rhinitis were observed at a high rate in

Table 6 The number of subjects according to the times of pulmonary function tests

\begin{tabular}{|c|c|c|c|c|c|c|c|c|c|c|c|}
\hline & & \multicolumn{8}{|c|}{ The times of pulmonary function tests } & \multirow{2}{*}{$\begin{array}{l}\text { Subjects excluded from } \\
\text { the analysis (1-3 times) }\end{array}$} & \multirow{2}{*}{$\begin{array}{l}\text { Subjects included in the } \\
\text { analysis (4-8 times) }\end{array}$} \\
\hline & & 1 & 2 & 3 & 4 & 5 & 6 & 7 & 8 & & \\
\hline Group 1 & $\mathrm{n}$ & 40 & 30 & 15 & 21 & 18 & 12 & 23 & 20 & 85 & 94 \\
\hline$(n=179)$ & $\%$ & 22.3 & 16.8 & 8.4 & 11.7 & 10.1 & 6.7 & 12.8 & 11.2 & 47.5 & 52.5 \\
\hline Group 2 & $\mathrm{n}$ & 77 & 35 & 36 & 36 & 31 & 51 & 47 & 45 & 148 & 210 \\
\hline$(n=358)$ & $\%$ & 21.5 & 9.8 & 10.1 & 10.1 & 8.7 & 14.2 & 13.1 & 12.6 & 41.3 & 58.7 \\
\hline Group 3 & $\mathrm{n}$ & 48 & 24 & 22 & 14 & 9 & 33 & 25 & 21 & 94 & 102 \\
\hline$(n=196)$ & $\%$ & 24.5 & 12.2 & 11.2 & 7.1 & 4.6 & 16.8 & 12.8 & 10.7 & 48.0 & 52.0 \\
\hline
\end{tabular}


Table 7 Characteristics of subjects included and excluded from the analyses of pulmonary function

\begin{tabular}{|c|c|c|c|c|c|c|c|c|c|c|}
\hline & \multirow[b]{2}{*}{$n$} & \multicolumn{3}{|c|}{ Age (y) } & \multicolumn{2}{|c|}{ Height $(\mathrm{cm})$} & \multicolumn{2}{|l|}{ FVC (I) } & \multicolumn{2}{|c|}{$\mathrm{FEV}_{1}$ (I) } \\
\hline & & Mean & SD & & Mean & SD & Mean & SD & Mean & SD \\
\hline \multicolumn{11}{|l|}{ Group 1} \\
\hline Subjects included & 94 & 47.3 & 7.4 & * & 153.2 & 4.8 & 2.71 & 0.31 & 2.33 & 0.26 \\
\hline Subjects excluded & 85 & 44.0 & 7.7 & * & 154.2 & 5.1 & 2.67 & 0.35 & 2.30 & 0.28 \\
\hline \multicolumn{11}{|l|}{ Group 2} \\
\hline Subjects included & 210 & 47.6 & 7.8 & $\dagger$ & 153.6 & 4.9 & 2.72 & 0.33 & 2.34 & 0.28 \\
\hline Subjects excluded & 148 & 43.8 & 8.4 & $\dagger$ & 154.3 & 5.4 & 2.67 & 0.32 & 2.29 & 0.27 \\
\hline \multicolumn{11}{|l|}{ Group 3} \\
\hline Subjects included & 102 & 46.1 & 8.4 & * & 153.2 & 4.6 & 2.67 & 0.30 & 2.33 & 0.23 \\
\hline Subjects excluded & 94 & 43.5 & 8.6 & * & 154.1 & 4.9 & 2.63 & 0.30 & 2.28 & 0.28 \\
\hline
\end{tabular}

areas close to the roads with a high traffic level in comparison with the areas away from the roads. ${ }^{25}{ }^{26}$ The prevalence rate of respiratory symptoms in group 1 was higher than that in groups 2 and 3, except for wheezing. The rates of these respiratory symptoms were higher in the areas with high air pollution. The trend test indicated a significant difference in persistent phlegm and breathlessness. Among the three groups, there were differences in age, years of residence in the area, job status, smoking habit, and housing structure. The results of logistic regression analysis arranging these factors showed a significant relation of persistent phlegm and breathlessness with the level of air pollution. The influences of outing hours in daily life and type of occupation should also be considered. Among the subjects of this study, there
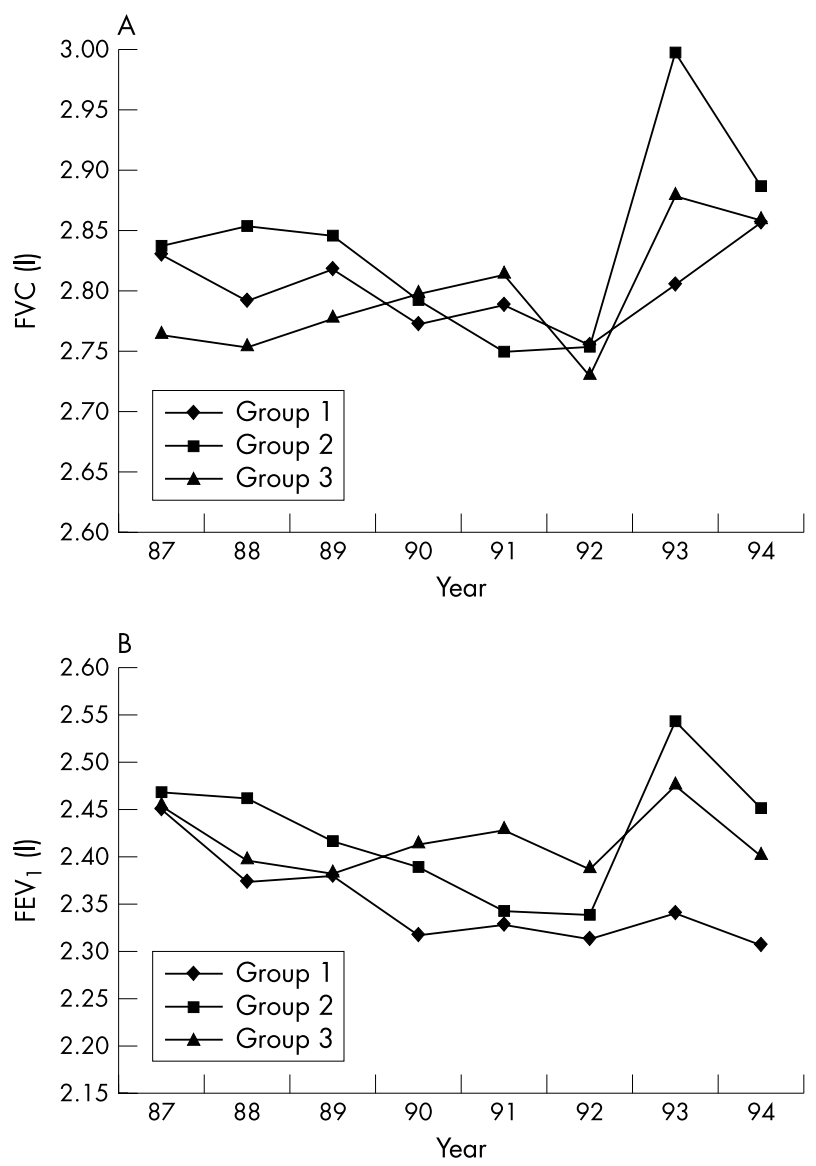

Figure 2 Mean levels of FVC (A) and FEV 1 (B) in each group at the examination, adjusted for age and height. were many who worked, and in most cases their jobs were clerical jobs, sales, and light work. It was also confirmed that more than $70 \%$ of them stayed at home 18 hours or longer, daily. Thus, the influence of outing hours may not be too large.

Concerning the relation between respiratory symptoms and pulmonary function, Sherman and colleagues ${ }^{27}$ reported that chronic cough and phlegm affected pulmonary function but that persistent wheezing and breathlessness did not show any relation in this regard. On the other hand, Kauffmann and colleagues ${ }^{28}$ conducted a 12-year follow up study and reported that respiratory symptoms, including cough, phlegm and dyspnoea, observed at the initial test were related to a lower initial level of $\mathrm{FEV}_{1}$, but that those symptoms were not
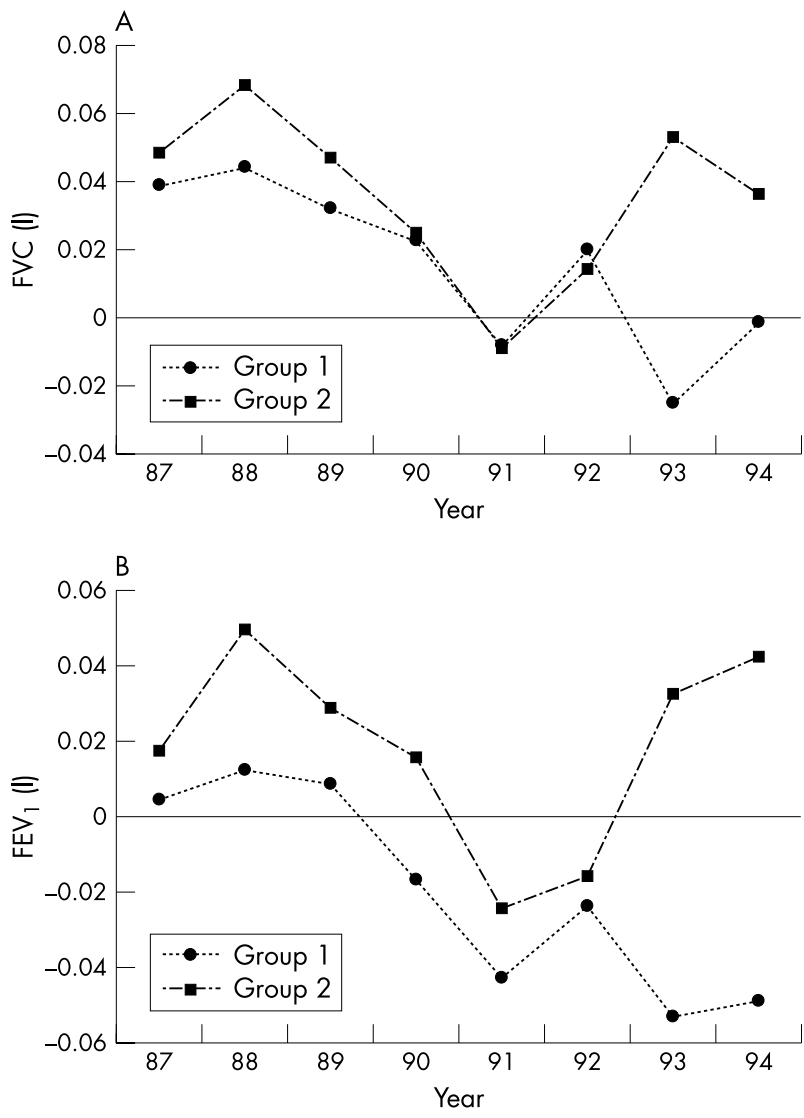

Figure 3 Mean levels of FVC (A) and $\mathrm{FEV}_{1}(\mathrm{~B})$ in each group at the examination, adjusted for age, square of age, height, years of residence in the area, housing structure, job status, and type of heater. The values in group 3 are subtracted from those in group 1 or group 2 . 
A

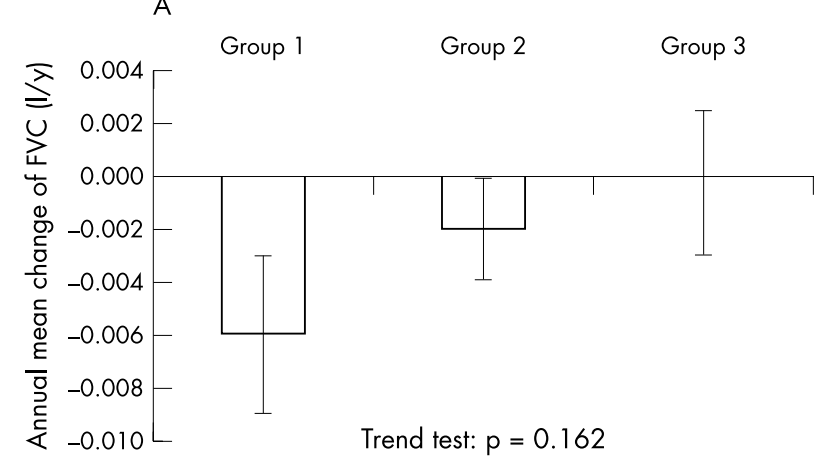

B

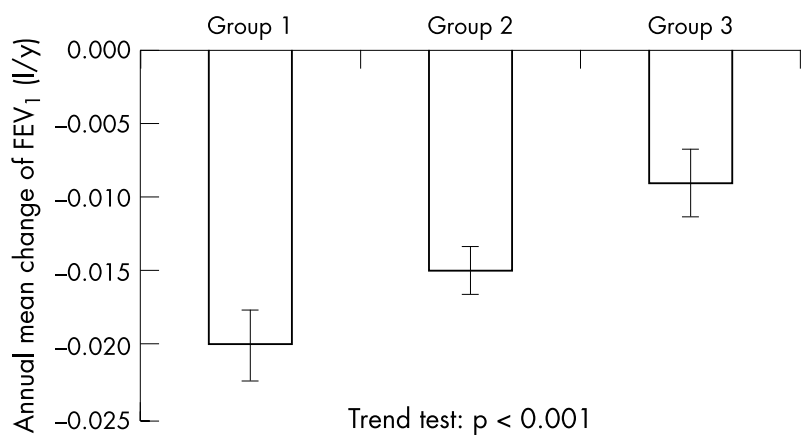

Figure 4 Annual mean change rates $(I / y)$ of $F V C(A)$ and $F E V_{1}(B)$ in the three groups. All values are mean (SEM), adjusted for group, pulmonary function test value in the initial test, age and height at the time of the initial test, number of years investigated, years of residence in the area, type of heater, housing structure, and job status.

related to subsequent decreases in pulmonary function. Since the major purpose of this study was to evaluate the influences of air pollution on long term changes in pulmonary function, we examined respiratory symptoms of subjects only at the initial test. Therefore, the incidence of respiratory symptoms during the follow up period remains unclear. However, we limited the number of females subjected to pulmonary function tests to healthy nonsmokers who had no history of respiratory diseases, thus the influence of respiratory symptoms on the changes in pulmonary function may not be too large.

Since FVC and $\mathrm{FEV}_{1}$ are often clinically used to assess longitudinal changes, these parameters were selected as the indices of pulmonary function in this study. AckermannLiebrich et al investigated the effects of air pollution on pulmonary function in eight districts in Switzerland. ${ }^{29}$ They reported that an increase of $10 \mu \mathrm{g} / \mathrm{m}^{3}$ in particulate matter less than $10 \mu \mathrm{m}$ in diameter $\left(\mathrm{PM}_{10}\right)$ resulted in a decrease of $3.4 \%$ in $\mathrm{FVC}$ and of $1.6 \%$ in $\mathrm{FEV}_{1}$ in healthy non-smokers. Chestnut $e t$ a $l^{30}$ reported that an increase of $34 \mu \mathrm{g} / \mathrm{m}^{3}$ in total suspended particles was related to a decrease of $2.25 \%$ in FVC and that the change in $\mathrm{FEV}_{1}$ was significant even though the change was small. Speizer ${ }^{31}$ showed that the effect of air pollution on respiratory health in adults was not clear because smoking and other interactive factors such as occupation and environmental exposure were also involved. To avoid uncontrollable variations in pulmonary function due to individual differences such as smoking history, we selected only healthy non-smoking adult females without a history of respiratory diseases as the subjects of this study. Furthermore, to evaluate the changes of pulmonary function values during the study period, we performed a longitudinal analysis over eight years. As a result, the influence of interactive factors such as exposure to air pollution in the past was considered small in our subjects. When a survey lasts a long time, a substantial number of subjects are inevitably lost to follow up due to change of address, etc. According to Tashkin and colleagues, ${ }^{32}$ change of address was the major reason for not receiving the second test, and the respiratory symptoms accounted for less than $1 \%$ of the reasons for drop-out. A considerable number of drop-outs also occurred during the follow up period in our study. Among those subjected to the initial pulmonary function test, the number of those included in the analysis of longitudinal changes and the number of those lost to follow up were compared. The results indicated that those analysed were significantly older in all three groups, indicating that those who were older had a stronger sense of participation in the study. However, considering that there was not much difference in the respiratory symptoms and initial level of pulmonary function between those analysed and the dropouts, the influence of drop-outs seemed to be small.

Pulmonary function tests were performed by the same method using the same spirometer throughout the study period. However, FVC and $\mathrm{FEV}_{1}$ increased from 1993 to 1994, particularly in group 2 . This may be due to a difference in the composition of the subjects examined or a difference in weather conditions, but the cause remains unclear. Many epidemiological studies have shown that exposure to air pollution for a short term was related to a decrease in pulmonary function. ${ }^{33-35}$ Tashkin and colleagues ${ }^{32}$ and van der Lende and colleagues ${ }^{36}$ reported the chronic effects of air pollution on the annual changes of pulmonary function value for a long term. Tashkin and colleagues ${ }^{32}$ compared three districts in which the levels of air pollution differed from each other. After adjustment for interactive factors, $\mathrm{FEV}_{1}$ decreased in females by $49.3 \mathrm{ml} /$ year and $50.1 \mathrm{ml} /$ year in two of the districts where air pollution levels were higher, but the decrease in the remaining district where the level was the lowest was $40.5 \mathrm{ml} /$ year. According to our study, group 1 showed the highest decrease rate $(0.020 \mathrm{l} /$ year $)$ of $\mathrm{FEV}_{1}$ followed by group 2 (0.015 l/year) and group 3 (0.009 l/year). The annual change of FVC showed a similar pattern (group 1 $>$ group $2>$ group 3 ), but FVC did not change in group 3 during the follow up period. The change of $\mathrm{FEV}_{1}$ was also smaller compared with the report by Tashkin and colleagues. ${ }^{32}$ As we obtained the annual mean respiratory volume change in each individual, the difference in the composition of the group examined may have not influenced the results. Since we selected only healthy non-smokers as the subjects of this study, the change of FVC might be too small to be detected. Furthermore, the difference in the method of investigation could also be responsible for the different results. To be more precise, we conducted a pulmonary function test every year and used those subjects whose data on four or more tests were available, while Tashkin and colleagues conducted only two tests with an interval of 5-6 years. ${ }^{32}$ In addition, it is necessary to take into consideration the ethnic difference as well as the differences in the device used for the pulmonary function tests, the air pollution level and quality, and the sensitivity of the subjects to air pollution. The increase in $\mathrm{FEV}_{1}$, especially in group 2 in 1993, seemed to be partly responsible for the difference from the result reported by Tashkin and colleagues. However, the difference in the annual changes of $\mathrm{FEV}_{1}$ between group 1 and group 3 was close to the difference between the area with the highest level of air pollution and that with the lowest level of air pollution in the study by Tashkin and colleagues.

Diesel exhaust particles (DEPs) are considered to account for about $30-50 \%$ of SPM, and most of DEPs consist of fine particles. Since fine particles reach the depth of lungs and precipitate there, they are expected to have a considerable 
influence on the living body, including the respiratory system. However, the mechanism of action of these particles has yet to be established. Repeated exposure to $\mathrm{NO}_{2}$ is known to induce inflammatory changes in the neutrophils in the lower airway, but reduction of pulmonary function is indicated to be temporary. ${ }^{37} 38$ On the other hand, inflammatory changes in the airway as well as in the whole body, and an increase in airway resistance were reported in humans experimentally exposed to diesel exhaust. ${ }^{39}{ }^{40}$ These studies suggested that long term exposure to $\mathrm{NO}_{2}$ and SPM was related to an increase in airway resistance and a chronic decrease in pulmonary function. The results of our study also show that the annual mean change of $\mathrm{FEV}_{1}$ is larger than that of FVC, indicating the considerable influence on airflow obstruction, including increased airway resistance. In this study, those who had lived in an area along the trunk roads showed a high prevalence rate of respiratory symptoms and more decreased pulmonary function. However, in these areas, both the concentrations of $\mathrm{NO}_{2}$ and SPM were high, so which pollutant had the most influence remains unclear. Hereafter, measurements of fine particles or diesel exhaust concentration may clarify the relation between air pollutants and pulmonary function. ${ }^{41}$

In summary, we investigated healthy adult females who lived in the Tokyo metropolitan area to clarify the chronic health effects of air pollution caused mainly by automobiles. According to our results, the subjects living in areas with high levels of air pollution showed higher prevalence rates of respiratory symptoms and a larger decrease of $\mathrm{FEV}_{\mathrm{I}}$ compared with those living in areas with low levels of air pollution. Considering the high traffic density in these areas, the effect of particulate matter found in automobile exhaust seems to be one of the factors responsible for the difference between other areas.

\section{ACKNOWLEDGEMENTS}

This study is part of an epidemiological study on the effects of air pollutants on health, performed by the Bureau of Public Health, Tokyo Metropolitan Government, Japan. Pulmonary function tests were conducted from 1987 to 1998, but the spirometer used for the tests had been changed in 1995. Therefore, we analysed the data of 8 years from 1987 to 1994, which were performed using the same device.

\section{Authors' affiliations}

K Sekine, M Shima, Y Nitta, M Adachi, Department of Public Health, Graduate School of Medicine, Chiba University, Chiba, Japan

\section{REFERENCES}

1 Tamura K, Ando M, Sagai M, et al. Estimation of levels of personal exposure to suspended particulate matter and nitrogen dioxide in Tokyo. Environ Sci 1996:4:37-51.

2 Shima M, Adachi M. Indoor nitrogen dioxide in homes along trunk roads with heavy traffic. Occup Environ Med 1998:55:428-33.

3 Nitta H, Sato T, Nakai S, et al. Respiratory health associated with exposure to automobile exhaust. I. Results of cross sectional studies in 1979, 1982, and 1983. Arch Environ Health 1993;48:53-8.

4 Vistal JJ. Health effects of diesel exhaust particulate emissions. Bull N Y Acad Med 1980;56:914-34.

5 Quality of Urban Air Review Group. Sources and emissions of primary particulate matter. In: Airborne particulate matter in the United Kingdom. Third report of the Quality of Urban Air Review Group. London: Department of Environment, 1996:37-55.

6 Sagai M, Furuyama A, Ichinose T. Biological effects of diesel exhaust particles (DEP). III. Pathogenesis of asthma like symptoms in mice. Radic Biol Med 1996;21:199-209.

7 Nitta $Y$, Adachi M, Kobayashi M, et al. A study of respiratory function in school children. II. Factors influencing spirometric function and pulmonary function growth. Japan J Public Health 1988;35:591-9.

8 Shima M, Nitta Y, Adachi M. Association of outdoor and indoor nitrogen dioxide with pulmonary function in school children. J Epidemiol 1994;4:137-46.
9 Gauderman WJ, McConnell R, Gilliland F, et al. Association between air pollution and lung function growth in southern California children. Am J Respir Crit Care Med 2000;162:1383-90.

10 Gauderman WJ, Gilliland F, Vora H, et al. Association between air pollution and lung function growth in southern California children. Results from a second cohort. Am J Respir Crit Care Med 2002; 166:76-84.

11 Evans RG, Webb K, Homan S, et al. Cross-sectional and longitudinal changes in pulmonary function associated with automobile pollution among bridge and tunnel officers. Am J Ind Med 1988;14:25-36.

12 Gamble J, Jones W, Minshall S. Epidemiological-environmental study of diesel bus garage workers: chronic effects of diesel exhaust on the respiratory system. Environ Res 1987;44:6-17.

13 Raaschou-Nielsen O, Nielsen ML, Gehl J. Traffic-related air pollution: exposure and health effects in Copenhagen street cleaners and cemetery workers. Arch Environ Health 1995:50:207-13.

14 Speizer FE, Ferris BGJ. Exposure to automobile exhaust. I. Prevalence of respiratory symptoms and disease. Arch Environ Health 1973;26:313-18.

15 Tollerud DJ, Weiss ST, Elting E, et al. The health effects of automobile exhaust. VI. Relationship of respiratory symptoms and pulmonary function in tunnel and turnpike workers. Arch Environ Health 1983;38:334-40.

16 Tokyo Metropolitan Government. Report on traffic density. Tokyo: Bureau of Construction, Road and Street Construction Division, 1990.

17 Hirano M, Maeda H, Ishii T, et al. Simple method for the simultaneous determination of nitric oxide and nitrogen dioxide. Environment and Measurement Technology 1985;12:32-9.

18 Ferris FG Jr. Epidemiology standardization project. Am Rev Respir Dis 1978;118:1-290.

19 Hosmer DW, Lemeshow S. Applied logistic regression, 2nd edn. New York: John Wiley \& Sons, 2000.

20 SAS Institute Inc. SAS/STAT user's guide, release 6.03. Cary, NC: SAS Institute, 1996.

21 Laxen DPH, Noordally E. Nitrogen dioxide distribution in street canyons. Atomos Environ 1987;21:1899-903.

22 Matsumoto $\mathrm{Y}$, Shindo J, Tamura K, et al. Spatio-temporal variations of daily average concentration of $\mathrm{NO}_{2}$ in an area with trunk roads. J Japan Soc Air Pollut 1994;29:41-54.

23 Ono $M$, Murakami $M$, Nitta $H$, et al. Epidemiological studies of air pollution and health effects in areas near roadways with heavy traffic in Tokyo. Japan J Public Health 1990;37:321-32.

24 Nakai S, Nitta H, Maeda K. Respiratory health associated with exposure to automobile exhaust. II. Personal $\mathrm{NO}_{2}$ exposure levels according to distance from the roadside. J Exposure Anal Environ Epidemiol 1990:5:125-36.

25 Duhme H, Weiland SK, Keil U, et al. The association between self-reported symptoms of asthma and allergic rhinitis and self-reported traffic density on street of residence in adolescents. Epidemiology 1996;7:578-82.

26 Tanaka $Y$, Nitta $Y$, Shima $M$, et al. The influence of air pollution around main arterial roads on the respiratory symptoms of schoolchildren. J Japan Soc Atmos Environ 1996;31:166-74.

27 Sherman CB, Xu X, Speizer FE, et al. Longitudinal lung function decline in subjects with respiratory symptoms. Am Rev Respir Dis 1992:146:855-9.

28 Kauffmann F, Drouet D, Lellouch J, et al. Twelve years spirometric changes among Paris area workers. Int J Epidemiol 1979;8:201-12.

29 Ackermann-Liebrich U, Leuenberger P, Schwartz J, et al. Lung function and long term exposure to air pollutants in Switzerland. Am J Respir Crit Care Med 1997; 155:122-9.

30 Chestnut LG, Schwartz J, Savitz DA, et al. Pulmonary function and ambient particulate matter. Arch Environ Health 1991;46:135-44

31 Speizer FE. Asthma and persistent wheeze in the Harvard Six Cities Study. Chest 1990:98:1918-58

32 Tashkin DP, Detels R, Simmons $M$, et al. The UCLA population studies of chronic obstructive respiratory disease. XI. Impact of air pollution and smoking on annual change in forced expiratory volume in one second. Am J Respir Crit Care Med 1994;149:1209-17.

33 Pope CA III, Dockery DW. Acute health effects of PM10 pollution on symptomatic and asymptomatic children. Am Rev Respir Dis 1992; 145: 1123-8.

34 Pope CA, Dockery DW, Spengler JD, et al. Respiratory health and PM 10 pollution: a daily time series analysis. Am Rev Respir Dis 1991;144:668-74.

35 Dockery DW, Ware JH, Ferris BG, et al. Change in pulmonary function in children associated with air pollution episodes. J Air Pollut Control Assoc 1982;32:937-42.

36 van der Lende R, Kok TJ, Peset-Reig R, et al. Decreases in VC and FEV 1 with time: indicators for effects of smoking and air pollution. Bull Eur Physiopathol Respir 1981;17:775-92.

37 Blomberg A, Krishna MT, Bocchino V, et al. The inflammatory effects of 2 ppm $\mathrm{NO}_{2}$ on the airways of healthy subjects. Am J Respir Crit Care Med 1997; 156:418-24

38 Blomberg A, Krishna MT, Helleday R, et al. Persistent airway inflammation but accommodated antioxidant and lung function responses after repeated daily exposure to nitrogen dioxide. Am J Respir Crit Care Med 1999;159:536-43.

39 Salvi S, Blomberg A, Rudell B, et al. Acute inflammatory responses in the airways and peripheral blood after short-term exposure to diesel exhaust in healthy human volunteers. Am J Respir Crit Care Med 1999:159.702-9.

40 Rudell B, Ledin MC, Hammarstrom U, et al. Effects on symptoms and lung functions in humans experimentally exposed to diesel exhaust. Occup Environ Med 1996;53:658-62.

41 Janssen NAH, de Hartog JJ, Hoek G, et al. Personal exposure to fine particulate matter in elderly subjects: relation between personal, indoor, and outdoor concentrations. J Air Waste Manage Assoc 2000;50:1133-43. 